\title{
COMPARATIVE STUDY ON THE LEAD ADSORPTION CHARACTERISTICS OF MODIFIED CORN STALK BIOCHAR
}

\author{
XU, H. Y. ${ }^{1}-$ MA, X. L. $.^{1 *}-$ WANG, B. ${ }^{1}-$ YUAN, M. Z. ${ }^{1}-$ SU, J. H. ${ }^{1}-$ WANG, Y. J. ${ }^{1 *}-$ GAO, H. J. ${ }^{2}$ \\ ${ }^{1}$ College of Resources and Environment, Jilin Agricultural University, Changchun 130118, \\ Jilin, China \\ ${ }^{2}$ Institute of Agricultural Environment and Resources Research, Jilin Academy of Agriculture \\ Sciences, Changchun 130033, Jilin, China \\ *Corresponding authors \\ e-mail/phonelfax: 491277643@qq.com/+86-180-0442-2753/+86-431-8453-1264 (X. Ma); \\ wyj0431@126.com/+86-135-0441-9456/+86-431-8453-1264 (Y. Wang) \\ (Received $1^{\text {st }}$ Sep 2021; accepted $23^{\text {rd }}$ Nov 2021)
}

\begin{abstract}
In this study, corn straw and modified corn straw impregnated with Potassium hydroxide $(\mathrm{KOH})$ were used as raw materials to prepare biochar $(\mathrm{BC})$ and modified biochar (K-BC). SEM, FTIR, EDS and other analytical methods were used to study the structure of $\mathrm{BC}$ and $\mathrm{K}-\mathrm{BC}$, and the equilibrium adsorption method was used to compare and study the characteristics of $\mathrm{BC}$ and $\mathrm{K}-\mathrm{BC}$ adsorbing $\mathrm{Pb}$. The results show that when the solution is weakly acidic ( $\mathrm{pH} \mathrm{5),} \mathrm{Quasi-second-order}$ kinetics can accurately describe the adsorption process of $\mathrm{Pb}\left(\mathrm{R}^{2}>0.9875\right)$; the Langmuir model fits well, indicating that $\mathrm{Pb}$ adsorption by biochar is mainly a single-layer adsorption; the results of thermodynamic tests $\Delta \mathrm{H}^{\circ}>0, \Delta \mathrm{S}^{\circ}>0, \Delta \mathrm{G}^{\circ}<0$ indicate that the adsorption of $\mathrm{Pb}$ by biochar is a spontaneous, endothermic, and disorderly increase process. Combining elemental analysis, specific surface area pore size determination, SEM, and EDS for the characterization of materials before and after adsorption, it can be seen that the difference between $\mathrm{BC}$ and $\mathrm{K}-\mathrm{BC}$ adsorption of $\mathrm{Pb}$ comes from the difference between the specific surface areas, pore structures and aromatic structures of the materials, accompanied by the ion exchange effect.
\end{abstract}

Keywords: corn stalk, biomass char, pH, alkali modification, lead, material characterization

\section{Introduction}

Lead $(\mathrm{Pb})$ is one of the three major heavy metal pollutants and is a heavy metal element that seriously harms human health. The ideal lead content in the human body is zero (Abdallah et al., 2019). Humans often bring lead into the human body by ingesting food and drinking tap water (Park et al., 2018). Lead poisoning is cumulative. After the long-term intake of lead, it will cause serious damage to the blood system and nervous system of the body, with the irreversible effects on children's health and intelligence (Dai and Jia, 2019). The lead production of China ranks first in the world. In recent years, the unreasonable extent of heavy metal mining and smelting, sewage irrigation, solid waste stacking, pesticides and fertilizers during the industrial development process has caused a large amount of heavy metals to enter the atmosphere, water bodies, and soil (Paranavithana et al., 2016). Heavy metals have become a global environmental pollution problem. At present, the main methods for removing heavy metals in water include chemical precipitation, ion exchange, adsorption, physical filtration and bioremediation (Abdelhafez et al., 2016). Adsorption method is a common method to remove heavy metals in wastewater (Deng et al., 2017). Due to the variety of adsorbent materials, the process is simple, and it is widely used in heavy metal polluted water bodies. 
Biomass char is produced by pyrolysis of biomass raw materials under oxygenlimited conditions. Biochar has rich oxygen-containing functional groups, large porosity, and high $\mathrm{pH}$. It has a good adsorption effect on heavy metals in water and soil, and has attracted widespread attention as a new material (Zhang et al., 2019a). Biocarbon raw materials have wide sources, low prices, and no secondary pollution, and are widely used for heavy metal pollution treatment (Xiao et al., 2018). The adsorption performance of biochar depends not only on the size of the pore structure of biochar, but also on the surface chemical properties of chemical functional groups and surface heteroatoms on the surface of biochar (Komnitsas et al., 2016; Zhao et al., 2020). Biochar can be modified by oxidative modification (Shen et al., 2018), load-bearing substance modification (Li et al., 2019), acid-base modification (Mahdi et al., 2019), etc. To modify its surface chemical properties and thus enhance its adsorption capacity. Cheng et al. (Cao et al., 2018) used biochar made from corn stover to remove $\mathrm{Pb}$ at a rate of $98.62 \%$. Cao et al. (Chi et al., 2017) found that the adsorption amount of $\mathrm{Pb}$ by wheat straw biochar is 2.58 times that of wheat straw. China is a large agricultural country. It produces about 243 million tons of corn stalks every year, which are discarded or burned at will, which has caused serious pollution to the environment (She et al., 2016). Using corn stalks as raw materials for preparing biomass charcoal can realize the resource utilization of agricultural wastes (Fahmi et al., 2018; Wang et al., 2019).

In this paper, corn straw (collected from Changchun, Jilin Province, China) was used as raw material to prepare biochar, and $\mathrm{KOH}$ soaked corn straw to prepare modified biochar. The adsorption characteristics of lead are studied in order to lay a foundational theory and provide technical reference for solving the pollution of heavy metal lead in wastewater.

\section{Materials and methods}

\section{Instruments}

SX2-4-10N muffle furnace (Shanghai Yetuo Instrumentation Co., Ltd.); LC-LXHL210D high-speed desktop centrifuge (Shanghai Decheng Instrument Factory); TAS990 atomic absorption spectrophotometer (Beijing General Analysis General Instrument Co., Ltd.); Vario-EL-III Elemental Analyzer (Elementar Company, Germany); 3H2000P Specific Surface Area, Aperture Analyzer (Beijing Best Company); Scanning Electron Microscope/X-Ray Energy Dispersion Analyzer (Japan Shimadzu Corporation); IRTracer-100 infrared spectrum (Japan Shimadzu Corporation), etc.

\section{Reagents and materials}

Main reagents

$\mathrm{Cu}\left(\mathrm{NO}_{3}\right)_{2}, \mathrm{~Pb}\left(\mathrm{NO}_{3}\right)_{2}, \mathrm{KOH}, \mathrm{NaOH}, \mathrm{NaNO}_{3}$ (all analytical reagents, Beijing Chemical Plant). Corn stalks come from Changchun, Jilin Province, China.

\section{Preparation of biochar}

Corn stalks passed through a 20-mesh sieve as raw materials, pyrolyzed at $450{ }^{\circ} \mathrm{C}$ for $2 \mathrm{~h}$ in a muffle furnace, cooled to room temperature, passed through a 60-mesh sieve, and marked as BC. 


\section{Preparation of alkali-modified biochar}

Put $10 \mathrm{~g}$ of corn stalk passed through a 20 mesh sieve into a $250 \mathrm{~mL}$ beaker, add $150 \mathrm{~mL}$ of $15 \% \mathrm{KOH}$ and stir every $8 \mathrm{~h}$, let stand for $24 \mathrm{~h}$, filter, and rinse the straw with deionized water. The $\mathrm{KOH}$ remaining on the surface was dried at $385^{\circ} \mathrm{C}$, then pyrolyzed at $450{ }^{\circ} \mathrm{C}$ for $2 \mathrm{~h}$ in a muffle furnace, cooled to room temperature, passed through a 60-mesh sieve, and marked as K-BC.

\section{Test design}

\section{Structural characterization and physical and chemical characteristics}

Refer to the "Charcoal and Charcoal Test Method" (GB/T17664-1999) for biochar asha content and $\mathrm{pH}$; the content of $\mathrm{C}, \mathrm{N}, \mathrm{H}$, and $\mathrm{O}$ on the surface of biochar shall be determined by elemental analyzer. Among them, $\mathrm{O}$ is obtained by subtractive method (Chen et al., 2014) specific surface area and pore structure are measured by specific surface area and pore size analyzer; functional groups on the surface of biochar are measured by infrared spectrometer (Gao et al., 2016); the microstructure of biochar is characterized by scanning electrons Microscopy/X-ray energy dispersive analysis was performed (Liang et al., 2015).

\section{Adsorption test}

Adsorption tests were performed under constant temperature and light, $150 \mathrm{r} \cdot \mathrm{min}^{-1}$ air-bath shaking conditions; $0.01 \mathrm{~mol} \cdot \mathrm{L}^{-1} \mathrm{NaNO}_{3}$ was used as the background electrolyte solution; the amount of biochar was $1.25 \mathrm{~g} \cdot \mathrm{L}^{-1}$, and the $\mathrm{pH}$ of the background solution. It was adjusted with $0.01 \mathrm{~mol} \cdot \mathrm{L}^{-1} \mathrm{HNO}_{3}$ and $\mathrm{NaOH}$ solution.

\section{Adsorption kinetics test}

Add $0.0625 \mathrm{~g}$ of $\mathrm{BC}$ and $\mathrm{K}-\mathrm{BC}$ samples to a $50 \mathrm{~mL}$ polyethylene centrifuge tube, add $\mathrm{pH} 5.0$, and the initial concentration is $400 \mathrm{mg} \cdot \mathrm{L}^{-1}$ lead nitrate solution, $25^{\circ} \mathrm{C}$ constant temperature shaking, sampled at $0,5,10,30,60,120,240,480,720,1440 \mathrm{~min}$, centrifuged at $10000 \mathrm{r} \cdot \mathrm{min}^{-1}$ for $10 \mathrm{~min}$, and used the supernatant for Atomic absorption spectrophotometer measures the concentration of $\mathrm{Pb}$.

\section{Adsorption thermodynamic test}

Add $0.0625 \mathrm{~g}$ of $\mathrm{BC}$ and $\mathrm{K}-\mathrm{BC}$ to $50 \mathrm{~mL}$ polyethylene centrifuge tubes, add nitric acid with a $\mathrm{pH}$ value of 5.0 and an initial concentration of 50,100, 200, 400, 600, $800 \mathrm{mg} \cdot \mathrm{L}^{-1}$ Salt lead was placed under the conditions of $15^{\circ} \mathrm{C}, 30{ }^{\circ} \mathrm{C}$ and $45^{\circ} \mathrm{C}$, shaken for $360 \mathrm{~min}$, centrifuged at $10000 \mathrm{r} \cdot \mathrm{min}^{-1}$ for $10 \mathrm{~min}$, the supernatant was taken and the concentration of $\mathrm{Pb}$ was determined by atomic absorption spectrophotometer.

\section{Effect of pH of background solution on $\mathrm{Pb}$ adsorption}

Add $0.0625 \mathrm{~g}$ of $\mathrm{BC}$ and $\mathrm{K}-\mathrm{BC}$ to a $50 \mathrm{~mL}$ polyethylene centrifuge tube. The $\mathrm{pH}$ of the background solution is $2.0,3.0,4.0,5.0,6.0$, and the initial concentration is $400 \mathrm{mg} \cdot \mathrm{L}^{-1}$ lead nitrate solution was shaken at $25^{\circ} \mathrm{C}$ for $6 \mathrm{~h}$, centrifuged at $10000 \mathrm{r} \cdot \mathrm{min}^{-1}$ for $10 \mathrm{~min}$, and the supernatant was measured by atomic absorption spectrophotometer. 


\section{Data analysis}

The adsorption capacity of the solution is calculated using the mass balance equation (Eq. 1):

$$
\mathrm{q}_{\mathrm{t}}=\frac{\left(\mathrm{c}_{\mathrm{o}}-\mathrm{c}_{\mathrm{t}}\right) \mathrm{v}}{\mathrm{m}}
$$

where $\mathrm{qt}$ is the adsorption capacity of $\mathrm{Pb}$ at time $\mathrm{t}\left(\mathrm{mg} \cdot \mathrm{g}^{-1}\right)$; $\mathrm{C} 0$ is the initial $\mathrm{Pb}$ concentration $\left(\mathrm{mg} \cdot \mathrm{L}^{-1}\right)$; $\mathrm{Ct}$ is the equilibrium concentration of $\mathrm{Pb}$ at time $\mathrm{t}\left(\mathrm{mg} \cdot \mathrm{L}^{-1}\right)$; $\mathrm{V}$ is nitric acid Volume of lead solution $(\mathrm{mL}) ; \mathrm{m}$ is the amount $(\mathrm{mg})$ of the adsorbent $\mathrm{BC}$ and K-BC added.

Adsorption kinetics was fitted using quasi-first-order kinetic equations (Eq. 2) and quasi-second-order kinetic equations (Eq. 3).

$$
\begin{gathered}
q_{t}=Q_{e_{1} 1}\left(1-e^{-k_{1} t}\right) \\
q_{t}=\frac{Q_{g, a}^{\mathbb{N}} k_{2} t}{1+Q_{g, a} k_{2} t} \text { (non-linear form) }
\end{gathered}
$$

in the formula: $\mathrm{qt}$ is the adsorption capacity of $\mathrm{Pb}$ at time $\mathrm{t}\left(\mathrm{mg} \cdot \mathrm{g}^{-1}\right)$; $\mathrm{Qe}, 1$ and $\mathrm{k} 1$ are quasi-first-order kinetic constants, which represent the adsorption equilibrium amount $\left(\mathrm{mg} \cdot \mathrm{g}^{-1}\right)$ and adsorption rate constant of $\mathrm{Pb}\left(\mathrm{min}^{-1}\right) ; \mathrm{Q}_{\mathrm{e}, 2}$ and $\mathrm{k}_{2}$ are quasi-second-order kinetic constants, which represent the adsorption equilibrium amount $\left(\mathrm{mg} \cdot \mathrm{g}^{-1}\right)$ and adsorption rate constant $\left(\mathrm{g} \cdot \mathrm{mg}^{-1} \cdot \mathrm{min}^{-1}\right)$ of $\mathrm{Pb}$, respectively.

The adsorption isotherm data was fitted using Langmuir equation (Eq.4) and Freundlich equation (Eq. 5):

$$
\begin{aligned}
& \mathrm{q}_{\mathrm{t}}=\frac{\mathrm{Q}_{\mathrm{g}, \mathrm{g}}^{\mathrm{N}} \mathrm{k} \mathrm{t}}{1+\mathrm{Q}_{\mathrm{g}, \mathrm{g}} \mathrm{k}_{\mathrm{z}} \mathrm{t}} \text { (non-linear form) } \\
& \mathrm{q}_{\mathrm{e}}=\mathrm{K}_{\mathrm{F}} \mathrm{C}_{\mathrm{t}}^{1 / \mathrm{n}} \text { (non-linear form) }
\end{aligned}
$$

where qe is the equilibrium adsorption amount $\left(\mathrm{mg} \cdot \mathrm{g}^{-1}\right)$ of $\mathrm{Pb}$; $\mathrm{qm}$ and $\mathrm{K}_{\mathrm{L}}$ are parameters of the Langmuir model, which respectively represent the maximum adsorption amount $\left(\mathrm{mg} \cdot \mathrm{g}^{-1}\right)$ and adsorption energy $\left(\mathrm{L} \cdot \mathrm{mg}^{-1}\right)$ of $\mathrm{Pb} ; \mathrm{K}_{\mathrm{F}}$ and $\mathrm{n}$ are parameters of the Freundlich model, and represent the adsorption capacity $\left(\mathrm{mg} \cdot \mathrm{g}^{-}\right.$ $\left.{ }^{1} \cdot\left(\mathrm{mg} \cdot \mathrm{L}^{-1}\right)^{-1 / n}\right)$ and adsorption strength of $\mathrm{Pb}$, respectively.

The adsorption thermodynamic parameters are standard free energy change $\left(\Delta \mathrm{G}^{\circ}, \mathrm{kJ}\right.$ $\left.\cdot \mathrm{mol}^{-1}\right)$, standard enthalpy change $\left(\Delta \mathrm{H}^{\circ}, \mathrm{kJ} \cdot \mathrm{mol}^{-1}\right)$, and standard entropy change $\left(\Delta \mathrm{S}^{\circ}\right.$, $\left.\mathrm{J} \cdot \mathrm{mol}^{-1} \cdot \mathrm{K}^{-1}\right)$.

Thermodynamic equation calculation:

$$
\begin{gathered}
\mathrm{K}_{\mathrm{d}}=\frac{\left(\mathrm{C}_{0}-\mathrm{C}_{\mathrm{t}}\right) \mathrm{V}}{\mathrm{C}_{\mathrm{t}} \mathrm{m}} \\
\ln \mathrm{K}_{\mathrm{d}}=\frac{\Delta \mathrm{S}^{\circ}}{\mathrm{R}}-\frac{\Delta \mathrm{H}^{\circ}}{\mathrm{RT}}
\end{gathered}
$$




$$
\Delta \mathrm{G}=\Delta \mathrm{H}^{\circ}-\mathrm{T} \Delta \mathrm{S}^{\circ}
$$

where $\mathrm{Kd}$ is the thermodynamic equilibrium constant $\left(\mathrm{mL} \cdot \mathrm{g}^{-1}\right), \mathrm{R}$ is the ideal gas constant $\left(8.314 \mathrm{~J} \cdot \mathrm{mol} \cdot \mathrm{K}^{-1}\right), \mathrm{T}$ is the reaction temperature $(\mathrm{K})$, and the $\Delta \mathrm{H}^{\circ}$ and $\Delta \mathrm{S}^{\circ}$ values are $\ln \mathrm{K}_{\mathrm{d}}-\mathrm{T}^{-1}$ The slope and intercept of the straight line in the 1 diagram.

\section{Results and discussion}

\section{$B C$ and $K-B C$ structural characterization and properties}

\section{Infrared spectral characterization}

Figure 1 shows the ir spectra of $\mathrm{BC}$ and $\mathrm{K}-\mathrm{BC}$. As can be seen from Figure 1, the main peaks of $\mathrm{BC}$ and $\mathrm{K}-\mathrm{BC}$ at $3400 \mathrm{~cm}^{-1}$ do not show significant deviation, but the intensity of K-BC peak decreases significantly. Through semi-quantitative analysis of the relative intensity of main absorption peaks of $\mathrm{BC}$ and $\mathrm{K}-\mathrm{BC}$, it decreases from 0.2755 to 0.1372 . Compared with $\mathrm{BC}$, the main adsorption peaks on the surface of $\mathrm{K}$ $\mathrm{BC}$ have changed: the $-\mathrm{OH}$ stretching vibration peaks of alcohols and phenols associated with intermolecular hydrogen bonding at $3400 \mathrm{~cm}^{-1}$ are weakened; the asymmetric aliphatic $\mathrm{CH}$ and The stretching vibration absorption peak of $-\mathrm{CH}_{2}$ symmetric aliphatic $\mathrm{CH}$ at $2850 \mathrm{~cm}^{-1}$ was weakened; the stretching vibration peaks of $\mathrm{C}=\mathrm{C}, \mathrm{C}=\mathrm{O}$ of benzene ring or aromatic heterocycle between $1620 \mathrm{~cm}^{-1}$ and 1400 $\mathrm{cm}^{-1}$ increased, and $1425 \mathrm{~cm}^{-1}$. The absorption peak of the stretching vibration of aromatic $\mathrm{C}=\mathrm{C}$ is obviously enhanced and merges with the absorption peak of $-\mathrm{OH}$ inplane bending vibration of the alcohol at $1362 \mathrm{~cm}^{-1}$; Si-O bonds are characterized at $1038 \mathrm{~cm}^{-1}$ and $780 \mathrm{~cm}^{-1}$ The absorption peaks of the stretching vibrations are also enhanced.

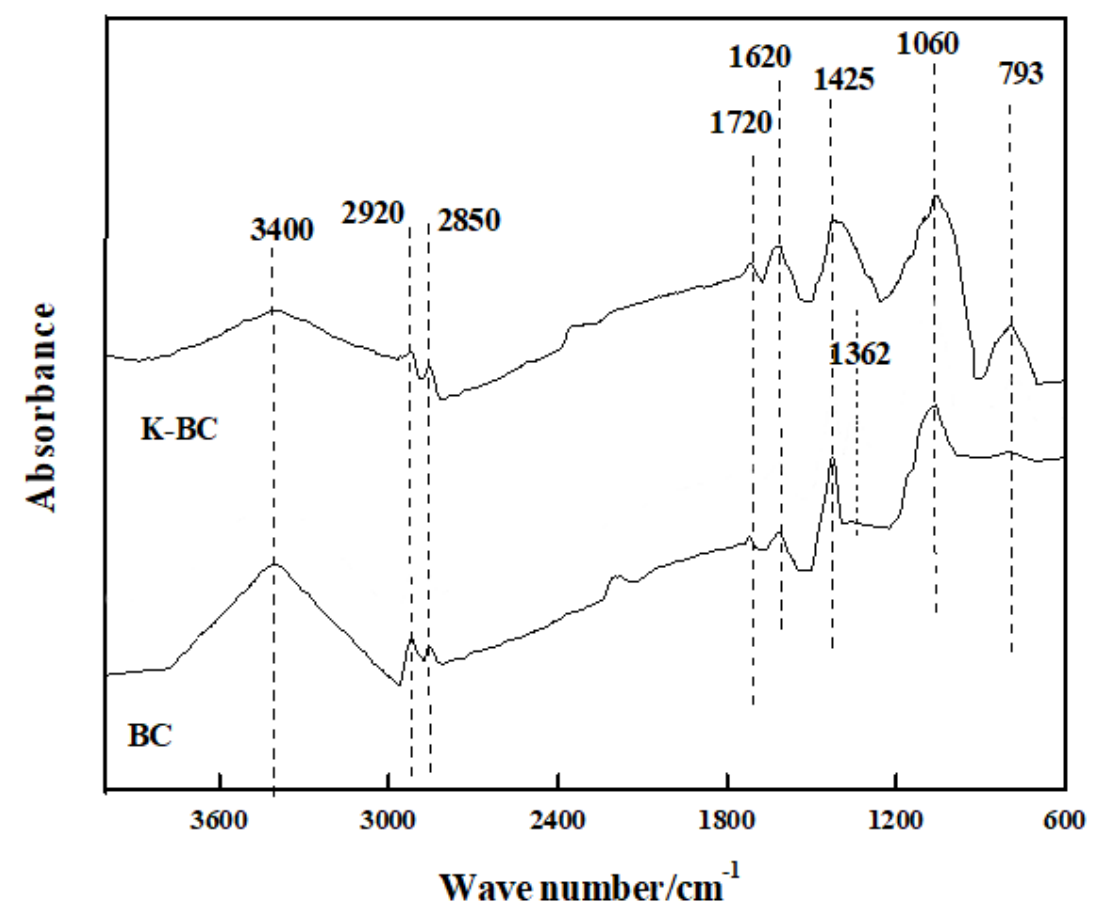

Figure 1. $B C$ and $K-B C$ infrared spectra. (a) $K-B C$; (b) $B C$. The picture shows the infrared spectrum of $\mathrm{Pb}$ after adsorption 
Table 1 shows the results of semi-quantitative analysis of the relative intensities of the main absorption peaks of $\mathrm{BC}$ and $\mathrm{K}-\mathrm{BC}$, and the number of functional groups can be compared quantitatively. Among them, $(2920+2850) /(1620+1425)$ can reflect the aromatic strength of biochar. It can be seen from Table 1 that compared with $\mathrm{BC}$, the $(2920+2850) /(1620+1425)$ ratio of $\mathrm{K}-\mathrm{BC}$ is significantly reduced, indicating that the carbonyl groups and aromatic structures contained in $\mathrm{K}-\mathrm{BC}$ are increased, while the relative content of aliphatic $\mathrm{CH}$ is decreased. It means that the alkali-soaked corn stalk can promote the increase of K-BC aromatization degree and selectively retain some of its oxygen-containing groups. Li et al. (Wang et al., 2016) found that the cation- $\pi$ action is one of the main mechanisms for biochar adsorption of heavy metals, that is, the higher the aromaticity of the biochar surface, the more $\pi$-conjugated aromatic structures, the stronger the cation- $\pi$ action, and the cation- $\pi$. The greater the contribution of action to heavy metal adsorption. In this study, K-BC has a higher degree of aromaticity than $\mathrm{BC}$ and can provide more active adsorption sites for cation- $\pi$ interactions. Therefore, the contribution of cation- $\pi$ interactions to $\mathrm{Pb} 2+$ in $\mathrm{K}-\mathrm{BC}$ may be higher than that of BC. Studies have shown that the inorganic mineral component $\mathrm{SiO} 2$ on the surface of biochar has an important contribution to the adsorption of heavy metals (Jian et al., 2015). At the same time, the absorption peaks of the Si-O bond stretching vibration in $\mathrm{K}-\mathrm{BC}$ have been enhanced, indicating that the amount of $\mathrm{SiO} 2$ on the surface of $\mathrm{K}-\mathrm{BC}$ More than BC.

Table 1. Influence of the relative intensity of the main absorption peaks of the infrared spectra of $B C$ and $K-B C$ (semi-quantitative)

\begin{tabular}{|c|c|c|c|c|c|c|c|c|}
\hline \multirow[b]{2}{*}{ Treatment } & \multicolumn{8}{|c|}{ Relative strength /\% } \\
\hline & $\begin{array}{l}3400 \\
/ \mathrm{cm}^{-1}\end{array}$ & $\begin{array}{l}2920 \\
/ \mathrm{cm}^{-1}\end{array}$ & $\begin{array}{l}2850 \\
/ \mathrm{cm}^{-1}\end{array}$ & $\begin{array}{l}1620 \\
/ \mathrm{cm}^{-1}\end{array}$ & $\begin{array}{l}1425 \\
/ \mathrm{cm}^{-1}\end{array}$ & $\begin{array}{l}1362 \\
/ \mathrm{cm}^{-1}\end{array}$ & $\begin{array}{l}1060 \\
/ \mathrm{cm}^{-1}\end{array}$ & $\begin{array}{c}793 \\
/ \mathrm{cm}^{-1}\end{array}$ \\
\hline $\mathrm{BC}$ & $\begin{array}{l}0.2755 \pm \\
0.0061 \mathrm{a}\end{array}$ & $\begin{array}{l}0.0555 \pm \\
0.0057 \mathrm{a}\end{array}$ & $\begin{array}{l}0.0287 \pm \\
0.0062 \mathrm{a}\end{array}$ & $\begin{array}{l}0.0528 \pm \\
0.0054 \mathrm{a}\end{array}$ & $\begin{array}{l}0.1651 \pm \\
0.0056 \mathrm{a}\end{array}$ & $\begin{array}{c}0.0534 \pm \\
0.0066\end{array}$ & $\begin{array}{l}0.2348 \pm \\
0.0069 \mathrm{a}\end{array}$ & $\begin{array}{l}0.1029 \pm \\
0.0052 \mathrm{a}\end{array}$ \\
\hline $\mathrm{K}-\mathrm{BC}$ & $\begin{array}{l}0.1372 \pm \\
0.0077 \mathrm{~b}\end{array}$ & $\begin{array}{l}0.0513 \pm \\
0.0060 \mathrm{a}\end{array}$ & $\begin{array}{l}0.0192 \pm \\
0.0063 \mathrm{a}\end{array}$ & $\begin{array}{c}0.1269 \pm \\
0.0071 \mathrm{ab}\end{array}$ & $\begin{array}{c}0.2343 \pm \\
0.0068 \mathrm{ab}\end{array}$ & - & $\begin{array}{l}0.2538 \pm \\
0.0053 \mathrm{a}\end{array}$ & $\begin{array}{l}0.1192 \pm \\
0.0065 \mathrm{a}\end{array}$ \\
\hline \multirow{2}{*}{ Treatment } & \multicolumn{8}{|c|}{ Ratio } \\
\hline & \multicolumn{4}{|c|}{$(2920+2850) / 1620$} & \multicolumn{4}{|c|}{$(2920+2850) /(1620+1425)$} \\
\hline $\mathrm{BC}$ & \multicolumn{4}{|c|}{1.5946} & \multicolumn{4}{|c|}{0.3864} \\
\hline $\mathrm{K}-\mathrm{BC}$ & \multicolumn{4}{|c|}{0.5556} & \multicolumn{4}{|c|}{0.1952} \\
\hline
\end{tabular}

"_-" means not detected. The data in the table are mean plus or minus standard deviation. Different letters after data in the same column indicate significant difference between different soil samples $(\mathrm{P}<0.05)$

\section{Determination of specific surface area, pore volume and pore size}

As can be seen from Table 2, the K-BC specific surface area of the modified biochar $\left(28.8272 \mathrm{~m} 2 \cdot \mathrm{g}^{-1}\right)$ is 9.6 times that of the unmodified biochar BC $\left(3.0065 \mathrm{~m} 2 \cdot \mathrm{g}^{-1}\right)$; the micropore volume $\left(0.0116 \mathrm{~mL} \cdot \mathrm{g}^{-1}\right)$ is 11.6 times the pore volume of $\mathrm{BC}\left(0.0010 \mathrm{~mL} \cdot \mathrm{g}^{-}\right.$ $\left.{ }^{1}\right)$; the average particle size of $\mathrm{K}-\mathrm{BC}(0.6878)$ is much smaller than the average particle size of BC (1.2030). It is shown that during the process of corn stalks being alkalized and impregnated and then cracked and carbonized, the number of micropores is larger and the specific surface area is larger, which is consistent with the SEM analysis result of Figure 2. The specific surface area of biochar will affect its ability to adsorb heavy metals (Wang et al., 2017a; Peng et al., 2017) Studied that the specific surface area of 
biochar is a key factor affecting its adsorption to heavy metals. The larger the specific surface area of biochar, the number of micropores. The more adsorption points that can be provided, the stronger the electrostatic adsorption capacity for heavy metals. Therefore, the reason why $\mathrm{K}-\mathrm{BC}$ adsorbs $\mathrm{Pb}$ better than $\mathrm{BC}$ is because $\mathrm{K}-\mathrm{BC}$ has a larger specific surface area and more microporous structure, which provides more adsorption sites for $\mathrm{Pb}$.

Table 2. Specific surface area and pore structure parameters of $B C$ and $K-B C$

\begin{tabular}{c|c|c|c|c}
\hline \multirow{2}{*}{ Treatment } & \multicolumn{4}{|c}{ Pore structure parameter } \\
\cline { 2 - 5 } & $\begin{array}{c}\text { BET specific surface } \\
\text { area } /\left(\mathbf{m}^{\mathbf{2}} \cdot \mathbf{g}^{-\mathbf{1}}\right)\end{array}$ & $\begin{array}{c}\text { Total pore volume } \\
/\left(\mathbf{m L} \cdot \mathbf{g}^{-1}\right)\end{array}$ & $\begin{array}{c}\text { Micropore volume } \\
/\left(\mathbf{m L} \cdot \mathbf{g}^{-\mathbf{1}}\right)\end{array}$ & $\begin{array}{c}\text { The average particle } \\
\text { size } /(\mathbf{m m})\end{array}$ \\
\hline $\mathrm{BC}$ & $3.0065 \mathrm{a}$ & $0.0015 \mathrm{a}$ & $0.0010 \mathrm{a}$ & $1.2030 \mathrm{a}$ \\
$\mathrm{K}-\mathrm{BC}$ & $28.8272 \mathrm{~b}$ & $0.0136 \mathrm{~b}$ & $0.0116 \mathrm{~b}$ & $0.6878 \mathrm{~b}$ \\
\hline
\end{tabular}

Different letters after data in the same column indicate significant difference between different soil samples $(\mathrm{P}<0.05)$

\section{Electron microscopy and energy spectrum analysis}

It can be seen from Figure 2 that the pore structures on the BC and K-BC surfaces have obvious differences. $\mathrm{BC}$ has a small number of pores and a relatively disordered distribution, and there are a small number of debris particles fused on the surface of the pores. The surface shape of $\mathrm{K}-\mathrm{BC}$ is relatively smooth, and there are more pore structures with honeycomb shape and relatively orderly arrangement.

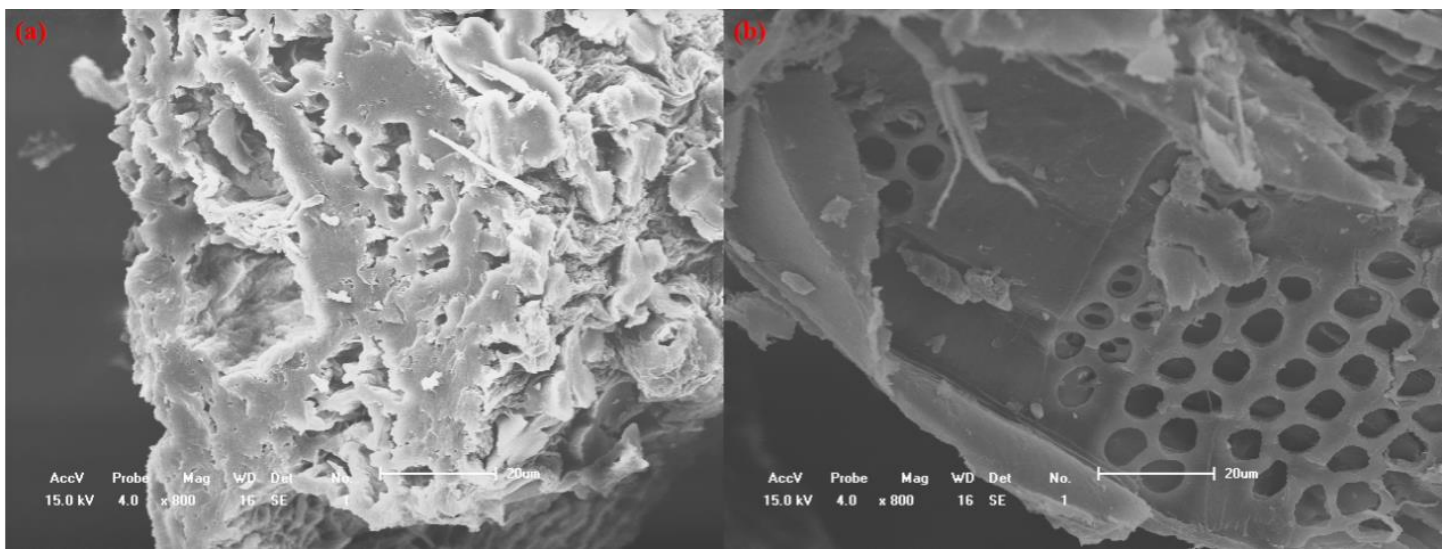

Figure 2. SEM images of initial biochar BC and alkalized biochar $K-B C$. (A) $B C$; (b) $K-B C$

As can be seen from Figure 3, the mass ratios of $\mathrm{Mg}, \mathrm{K}, \mathrm{C}$, and $\mathrm{O}$ in $\mathrm{BC}$ are $4.44 \%$, $2.08 \%, 33.69 \%$, and $45.93 \%$, and the mass ratios of $\mathrm{Mg}, \mathrm{K}, \mathrm{C}$, and $\mathrm{O}$ in $\mathrm{K}-\mathrm{BC}$ are $3.23 \%, 2.99 \%, 46.37 \%, 35.56 \%$. It can be seen from Figure 4 that when K-BC adsorbs $\mathrm{Pb}$, the peaks of $\mathrm{Mg}, \mathrm{O}, \mathrm{K}$, and $\mathrm{C}$ are significantly reduced, indicating that the process of adsorbing $\mathrm{Pb}$ is related to the loss of substances such as $\mathrm{Mg}, \mathrm{O}, \mathrm{K}$, and $\mathrm{C}$; the decrease in $\mathrm{O}$ peak may be due to In the biochar, carbonates reacted with $\mathrm{Pb}$, resulting in a decrease in the $\mathrm{O}$ content; due to the lower adsorption rate of $\mathrm{K}-\mathrm{BC}$ to $\mathrm{Pb}$, the peak of $\mathrm{Pb}$ appeared smaller; the mass fractions of elements such as $\mathrm{Na}, \mathrm{Mg}$, and $\mathrm{K}$ There are 
obvious changes, indicating that ion exchange has an important effect on the adsorption process (Zhang et al., 2019b).

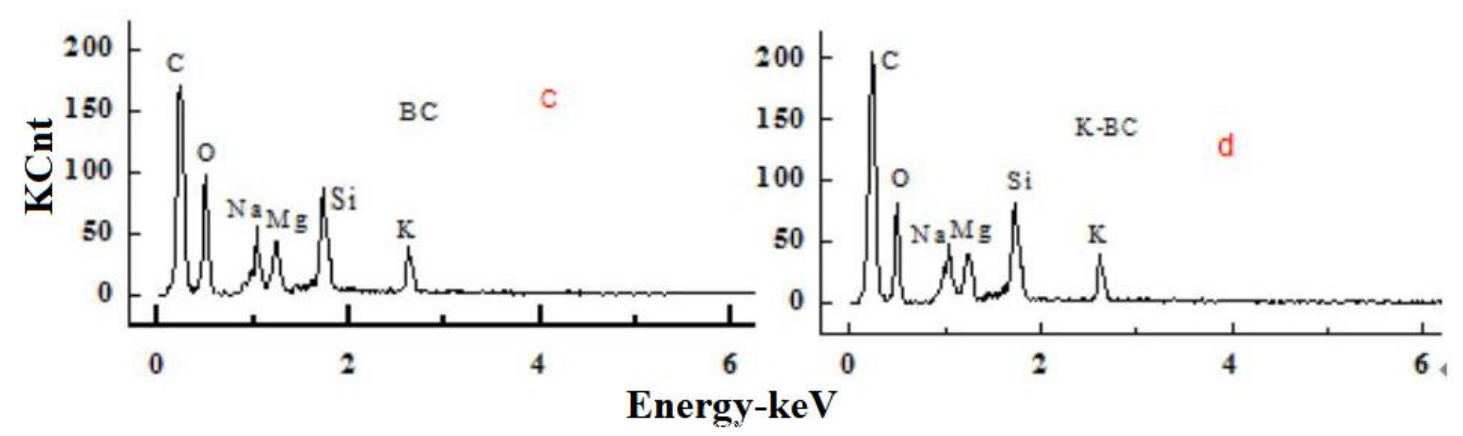

Figure 3. EDS diagram of $B C$ and $K-B C$. EDS diagrams for $B C$ and $K-B C$. (c) $B C$; (d) $K-B C$. As shown in the figure, both modified and unmodified biochar contain high content of $C$ and $O$ and trace mineral composition ( $\mathrm{Na}, \mathrm{Mg}, \mathrm{Si}, \mathrm{K})$ on the surface

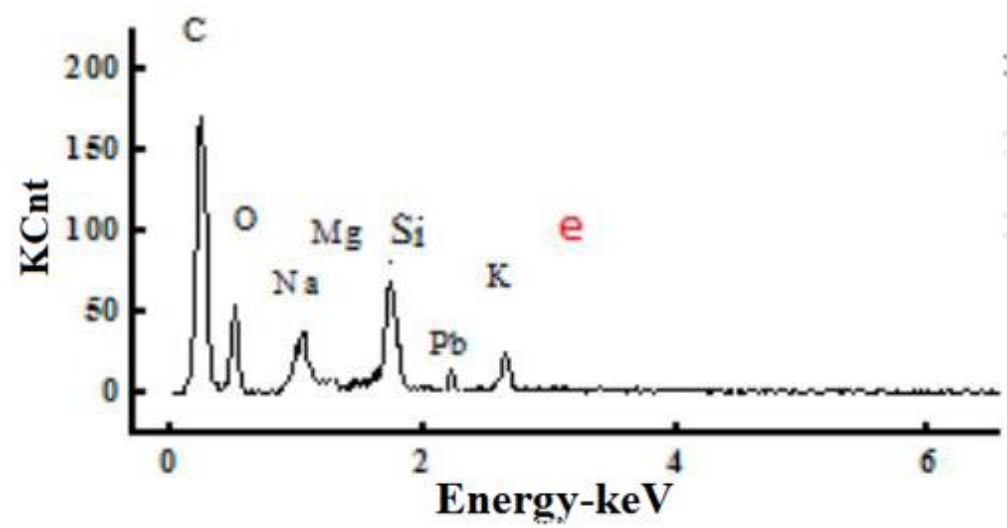

Figure 4. EDS diagram of $P b$ adsorption by $K-B C$. As shown in the figure, the content of $C$ and $O$ in the adsorbed $K-B C$ decreased significantly, and the trace element $K$ also decreased

\section{Study on the adsorption characteristics of $B C$ and $K-B C$ to $P b$}

Study on the adsorption kinetics of Pb

The time-varying curve of BC and K-BC's adsorption of $\mathrm{Pb}$ is shown in Figure 5. It can be seen from Figure 5 that the adsorption process of $\mathrm{Pb}$ by $\mathrm{BC}$ and $\mathrm{K}-\mathrm{BC}$ is similar, 0-30 min is the rapid adsorption stage, $\mathrm{BC}$ and $\mathrm{K}-\mathrm{BC}$ provide a large number of adsorption sites for $\mathrm{Pb}$ at the initial adsorption stage, and $\mathrm{BC}$ and $\mathrm{K}-\mathrm{BC}$ are adsorbed at $30 \mathrm{~min}$. adsorption of $\mathrm{Pb}$ was $111.72 \mathrm{mg} \cdot \mathrm{g}^{-1}$ and $120.99 \mathrm{mg} \cdot \mathrm{g}^{-1}$, accounting for $93.18 \%$ and $92.45 \%$ of the total adsorption; with the increase of the adsorption time, the adsorption sites on the surface of biochar tend to be saturated, $\mathrm{Pb}$ diffuses into the interior of the biochar, the diffusion resistance increases, and the adsorption amount stabilizes. It is a slow adsorption process within 30 360 min; the adsorption equilibrium at $360 \mathrm{~min}$, the maximum adsorption amounts of $\mathrm{BC}$ and $\mathrm{K}-\mathrm{BC}$ to $\mathrm{Pb}$ are $119.89 \mathrm{mg} \cdot \mathrm{g}^{-1}$ and $130.87 \mathrm{mg} \cdot \mathrm{g}^{-1}$. After the biochar was modified with alkali, the basic groups increased, which promoted the chemisorption of $\mathrm{Pb}$ (Kalderis et al., 2017), and the adsorption amount of K-BC increased by $9.16 \%$ compared with that of $\mathrm{BC}$. 


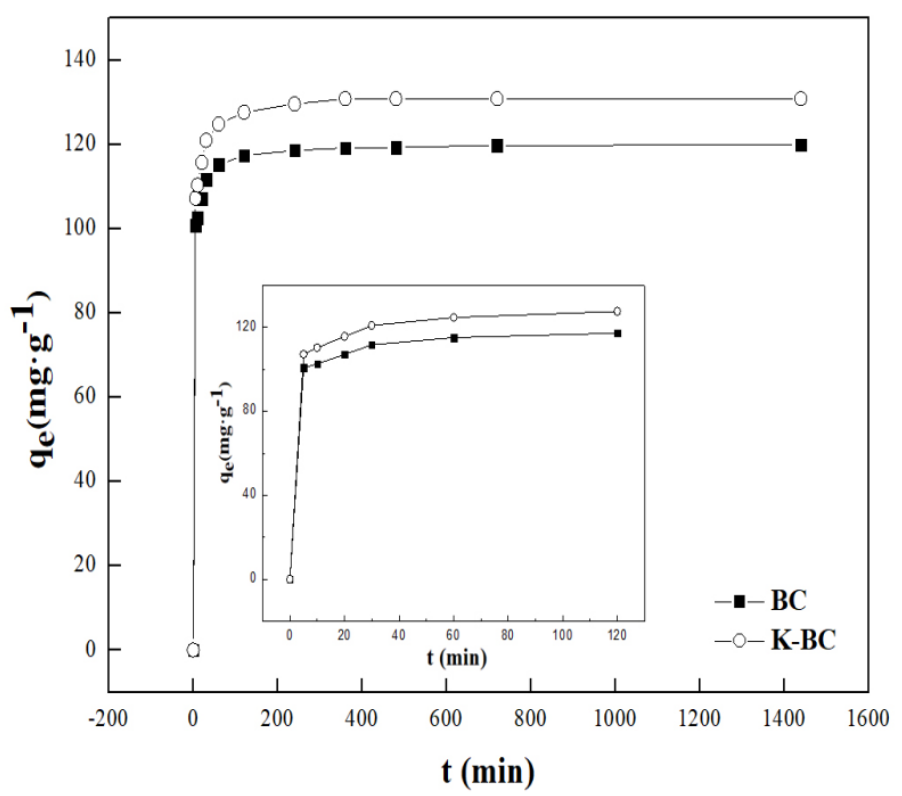

Figure 5. The adsorption kinetic curve qe of $B C$ and $K-B C$ is the amount of lead adsorbed at time t, $\mathrm{mg} \cdot \mathrm{g}^{-1}$. Take t as 0, 5, 15, 30, 60, 100, 200,600, 800, 1000, 1200, 1400 and $1600 \mathrm{~min}$ to draw the adsorption curve

The $\mathrm{BC}$ and $\mathrm{K}-\mathrm{BC}$ adsorption kinetics of $\mathrm{Pb}$ were fitted with quasi-first-order kinetic equations and quasi-second-order kinetic equations. The fitting parameters are shown in Table 3. In general, the better the model is, the greater the $\mathrm{R}$ value is. As can be seen from Table 3, the adsorption correlation coefficients of $\mathrm{Pb}$ in $\mathrm{BC}$ and $\mathrm{K}-\mathrm{BC}$ by the quasi-second-order kinetic equation are 0.9969 and 0.9964, respectively, which are larger than those of the quasi-first-order kinetic equation ( $\mathrm{r}$ is 0.9878 and 0.9854 , respectively). The fitted equilibrium adsorption capacities of $118.2 \mathrm{mg} \cdot \mathrm{kg}^{-1}$ and $129.2 \mathrm{mg} \cdot \mathrm{kg}^{-1}$ were close to the experimental values.

Therefore, it can be inferred that the adsorption of $\mathrm{BC}$ and $\mathrm{K}-\mathrm{BC}$ on $\mathrm{Pb}$ pair is a multiple adsorption process of external liquid film diffusion, surface adsorption and internal particle diffusion, rather than a single adsorption process. and the fitted equilibrium adsorption amounts of $118.2 \mathrm{mg} \cdot \mathrm{g}^{-1}$ and $129.2 \mathrm{mg} \cdot \mathrm{g}^{-1}$ were close to the experimental values.

It is inferred that the adsorption of $\mathrm{Pb}$ pairs by $\mathrm{BC}$ and $\mathrm{K}-\mathrm{BC}$ is a multiple adsorption process of external liquid film diffusion, surface adsorption, and particle internal diffusion (Wang et al., 2017b), and is not a single adsorption process.

Table 3. Adsorption kinetic parameters of $B C$ and $K-B C$ for $P b$

\begin{tabular}{|c|c|c|c|c|c|c|}
\hline \multirow[b]{2}{*}{ Treatment } & \multicolumn{3}{|c|}{ Quasi-first order kinetic equation } & \multicolumn{3}{|c|}{ Quasi-second order kinetic equation } \\
\hline & $\begin{array}{c}\mathrm{Q}_{\mathrm{e}, \mathrm{1}} / \\
\mathrm{mg} \cdot \mathrm{g}^{-1}\end{array}$ & $\begin{array}{c}\mathrm{K}_{1} / \\
\mathrm{g} \cdot \mathrm{mg}^{-1} \cdot \mathbf{h}^{-1}\end{array}$ & $\mathbf{R}$ & $\begin{array}{c}\mathrm{Q}_{\mathrm{e}, 2 /} \\
\mathrm{mg} \cdot \mathrm{g}^{-1}\end{array}$ & $\begin{array}{c}\mathrm{K}_{2} / \\
\mathrm{g} \cdot \mathrm{mg}^{-1} \cdot \mathbf{h}^{-1}\end{array}$ & $\mathbf{r}$ \\
\hline $\mathrm{BC}$ & 115.7 & 0.369 & $0.988 * *$ & 118.2 & 0.007 & $0.997 * *$ \\
\hline $\mathrm{K}-\mathrm{BC}$ & 126.0 & 0.337 & $0.985 * *$ & 129.2 & 0.006 & $0.996 * *$ \\
\hline
\end{tabular}

$\mathrm{Q}_{\mathrm{e}, 1}$ and $\mathrm{Q}_{\mathrm{e}, 2}$ are the theoretical equilibrium adsorption capacity $\left(\mathrm{mg} \cdot \mathrm{g}^{-1}\right), \mathrm{K}_{1}, \mathrm{~K}_{2}$ and the primary and secondary adsorption rate constant $\left(\mathrm{g} \cdot \mathrm{mg}^{-1} \cdot \mathrm{h}^{-1}\right)$. ** indicates a very significant correlation $(\mathrm{p} \leq 0.001) . \mathrm{r}$ means the correlation coefficient between Quasi-first order kinetic equation and Quasi-second order kinetic equation 
Study on the thermodynamics of $P b$ adsorption by $B C$ and $K-B C$

In the test temperature range $\left(15^{\circ} \mathrm{C}, 30{ }^{\circ} \mathrm{C}, 45^{\circ} \mathrm{C}\right)$, the adsorption isotherms of $\mathrm{BC}$ and $\mathrm{K}-\mathrm{BC}$ on $\mathrm{Pb}$ are shown in Figure 6. It can be seen from Figure 6 that when the initial concentration of $\mathrm{Pb}$ is less than $400 \mathrm{mg} \cdot \mathrm{L}^{-1}$, the equilibrium adsorption of $\mathrm{Pb}$ by $\mathrm{BC}$ and $\mathrm{K}-\mathrm{BC}$ increases with the increase of the initial concentration of the solution, and when the concentration of $\mathrm{Pb}$ is greater than $400 \mathrm{mg} \cdot \mathrm{L}^{-1}$, the equilibrium. The adsorption amount remained basically unchanged, indicating that the adsorption equilibrium was reached when the $\mathrm{Pb}$ concentration was $400 \mathrm{mg} \cdot \mathrm{L}^{-1}$. Giles et al. (Sing et al., 1985) divided the adsorption isotherm into four types of curves: "S, L, H, C" according to the initial slope of the adsorption isotherm. The adsorption isotherms of $\mathrm{Pb}$ by BC and K-BC were "L" Type, which belongs to the case of monolayer adsorption. With the increase of the reaction temperature, the adsorption amount of $\mathrm{Pb}$ by $\mathrm{BC}$ and $\mathrm{K}-\mathrm{BC}$ also increased, indicating that the adsorption process is an endothermic process, and the increase in temperature is favorable for the adsorption of $\mathrm{Pb}$.

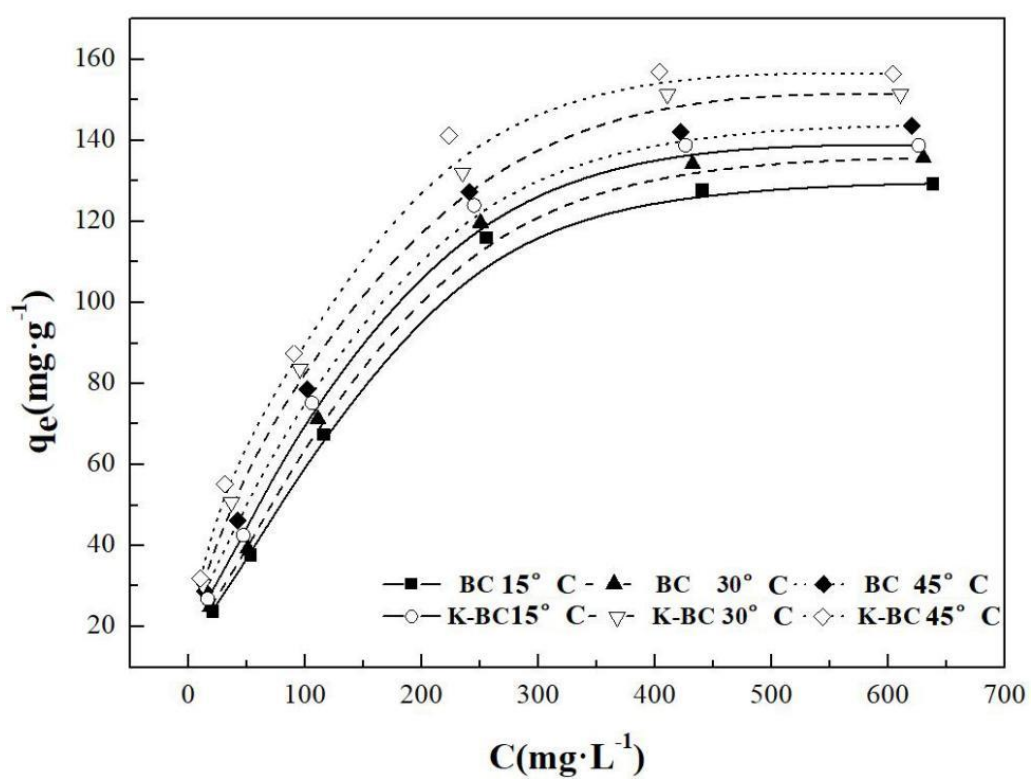

Figure 6. Adsorption isotherms of $P b$ by $B C$ and $K-B C$. Adsorption isotherm curves of lead in $B C$ and $K-B C$. qe is the lead adsorption capacity $m g \cdot g^{-1}$; $C$ is the mass concentration of lead in the equilibrium solution system, $m g \cdot L^{-1}$. The initial concentrations of Pb were 20, 50, 100, 150, $200,250,300,350,400,450,500,550,600$ and $650 \mathrm{mg} \cdot \mathrm{L}^{-1}$, and the test temperatures were $15^{\circ} \mathrm{C}, 30^{\circ} \mathrm{C}$ and $45^{\circ} \mathrm{C}$

The Langmuir model and Freundlich model can describe the distribution behavior between adsorbent and adsorbent at a certain temperature (Zhu et al., 2015). The fitting parameters of the adsorption isotherms of $\mathrm{BC}$ and $\mathrm{K}-\mathrm{BC}$ adsorbing $\mathrm{Pb}$ are shown in Table 4. It can be seen from Table 4 that the Langmuir model $(0.986<\mathrm{r}<0.991)$ is more suitable for fitting $\mathrm{BC}$ and $\mathrm{K}-\mathrm{BC}$ to $\mathrm{Pb}$ adsorption process than the Freundlich model $(0.953<\mathrm{r}<0.970)$. From the Langmuir model, we can know that $\mathrm{K}-\mathrm{BC}$ to $\mathrm{Pb}$ The adsorption capacity of $\mathrm{Pb}$ is higher than that of $\mathrm{Pb}$ by $\mathrm{BC}$, which indicates that the adsorption of $\mathrm{Pb}$ by biochar is more similar to that of single molecular layer. The dimensionless parameter separation factor $\mathrm{KL}\left(0<\mathrm{K}_{\mathrm{L}}<1\right)$ indicates that the adsorption of $\mathrm{Pb}$ by $\mathrm{BC}$ and $\mathrm{K}-\mathrm{BC}$ is spontaneous. 
Table 4. $B C$ and $K$-BC adsorption isotherm parameters

\begin{tabular}{|c|c|c|c|c|c|c|c|}
\hline \multirow[b]{2}{*}{ Treatment } & \multirow[b]{2}{*}{ Temperature $\left({ }^{\circ} \mathrm{C}\right)$} & \multicolumn{3}{|c|}{ Langmuir parameters } & \multicolumn{3}{|c|}{ Freundlich parameters } \\
\hline & & $\begin{array}{c}\mathrm{qm} / \\
\mathrm{mg} \cdot \mathrm{g}^{-1}\end{array}$ & $\begin{array}{c}\mathrm{K}_{\mathrm{L}} / \\
\mathbf{L} \cdot \mathbf{m g}^{-\mathbf{1}}\end{array}$ & $\mathbf{r}$ & $\mathbf{n}$ & $\mathbf{K}_{\mathbf{f}}$ & $\mathbf{r}$ \\
\hline \multirow{3}{*}{$\mathrm{BC}$} & 15 & 168.3 & 0.007 & $0.986 * *$ & 2.282 & 8.448 & $0.953 * *$ \\
\hline & 30 & 175.1 & 0.007 & $0.989 * *$ & 2.299 & 9.067 & $0.958 * *$ \\
\hline & 45 & 174.2 & 0.009 & $0.990 * *$ & 2.564 & 12.831 & $0.954 * *$ \\
\hline \multirow{3}{*}{$\mathrm{K}-\mathrm{BC}$} & 15 & 174.1 & 0.008 & $0.989 * *$ & 2.442 & 10.988 & $0.957 * *$ \\
\hline & 30 & 179.2 & 0.011 & $0.991 * *$ & 2.675 & 15.072 & $0.970 * *$ \\
\hline & 45 & 180.9 & 0.013 & $0.987 * *$ & 2.862 & 18.351 & $0.965 * *$ \\
\hline
\end{tabular}

$\mathrm{Kf}$ is the Freundlich equilibrium constant; $\mathrm{n}$ is the constant characterizing the adsorption strength, ** indicates extremely significant correlation $(\mathrm{p} \leq 0.001) ; \mathrm{r}$ means correlation coefficient for the Freundlich and Langmuir equation; qm is the theoretical maximum adsorption amount, $\left(\mathrm{mg} \cdot \mathrm{g}^{-1}\right)$; $\mathrm{KL}$ is the adsorption affinity coefficient, $\left(\mathrm{L} \cdot \mathrm{mg}^{-1}\right)$

Table 5 shows the thermodynamic parameters of $\mathrm{BC}$ and $\mathrm{K}-\mathrm{BC}$ adsorption of $\mathrm{Pb}$. It can be seen from Table 5 that at the test concentration $\left(50 \sim 800 \mathrm{mg} \cdot \mathrm{L}^{-1}\right)$ and test temperature $\left(15^{\circ} \mathrm{C}, 30^{\circ} \mathrm{C}, 45^{\circ} \mathrm{C}\right), \Delta \mathrm{H}^{\circ}>0$ indicates that $\mathrm{BC}$ and $\mathrm{K}-\mathrm{BC}$ adsorb $\mathrm{Pb}$ as an endothermic process, and increasing the temperature is beneficial The progress of the adsorption process indicates that the adsorption is a process of chemical bonding; $\Delta \mathrm{S}^{\circ}>0$ indicates that the adsorption is an irreversible process; $\Delta \mathrm{G}^{\circ}$ can reflect the driving force of the adsorption process (Liu et al., 2019), $\Delta \mathrm{G}^{\circ}<0$ indicates that $\mathrm{BC}$ and $\mathrm{K}-\mathrm{BC}$ adsorb $\mathrm{Pb}$ The process is spontaneous, and the absolute value of $\Delta \mathrm{G}^{\circ}$ gradually increases, indicating that the temperature increase promotes the reaction.

Table 5. Thermodynamic parameters of $B C$ and $K-B C$ adsorption of $P b$

\begin{tabular}{|c|c|c|c|c|c|c|}
\hline \multirow{2}{*}{ Treatment } & \multirow{2}{*}{$\begin{array}{c}C \\
\left(m L \cdot g^{-1}\right)\end{array}$} & \multirow{2}{*}{$\begin{array}{c}\Delta \mathbf{H} \\
\left(\mathrm{kJ} \cdot \mathrm{mol}^{-1}\right)\end{array}$} & \multirow{2}{*}{$\begin{array}{c}\Delta S \\
\left(\mathrm{~J} \cdot \mathrm{mol}^{-1} \cdot \mathbf{K}^{-1}\right)\end{array}$} & \multicolumn{3}{|c|}{$\Delta G\left(k J \cdot \mathrm{mol}^{-1}\right)$} \\
\hline & & & & $15^{\circ} \mathrm{C}$ & $30^{\circ} \mathrm{C}$ & $45^{\circ} \mathrm{C}$ \\
\hline \multirow{6}{*}{$\mathrm{BC}$} & 50 & 13.38 & 103.56 & -16.44 & -18.00 & -19.55 \\
\hline & 100 & 10.41 & 89.25 & -15.29 & -16.63 & -17.97 \\
\hline & 200 & 6.85 & 75.48 & -14.89 & -16.02 & -17.15 \\
\hline & 400 & 3.63 & 62.33 & -14.32 & -15.25 & -16.19 \\
\hline & 600 & 3.64 & 58.73 & -13.28 & -14.16 & -15.04 \\
\hline & 800 & 3.30 & 54.63 & -12.44 & -13.26 & -14.07 \\
\hline \multirow{6}{*}{$\mathrm{K}-\mathrm{BC}$} & 50 & 20.86 & 131.63 & -17.05 & -19.02 & -20.00 \\
\hline & 100 & 16.59 & 113.19 & -16.01 & -17.71 & -19.41 \\
\hline & 200 & 7.64 & 80.04 & -15.42 & -16.62 & -17.82 \\
\hline & 400 & 5.52 & 69.79 & -14.58 & -15.62 & -16.67 \\
\hline & 600 & 4.43 & 62.51 & -13.58 & -14.51 & -15.45 \\
\hline & 800 & 3.89 & 57.52 & -12.67 & -13.54 & -14.40 \\
\hline
\end{tabular}

$\mathrm{C}$ is the concentration; $\Delta \mathrm{G}$ is the Gibbs free energy, $\left(\mathrm{kJ} \cdot \mathrm{mol}^{-1}\right) ; \Delta \mathrm{H}$ is the standard enthalpy change, $\left(\mathrm{kJ} \cdot \mathrm{mol}^{-1}\right) ; \Delta \mathrm{S}$ is the standard entropy change, $\left(\mathrm{kJ} \cdot \mathrm{mol}^{-1} \cdot \mathrm{K}^{-1}\right)$

\section{Effect of different $p H$ of background solution on $\mathrm{Pb}$ adsorption}

$\mathrm{pH}$ can affect the adsorption of heavy metals by biochar by affecting the surface charge of biochar, the dissolution of mineral components, and the presence of heavy 
metal ions (Yang et al., 2019) (Fig. 7). Changes in the amount of $\mathrm{Pb}$ adsorbed by BC and $\mathrm{K}-\mathrm{BC}$ under different $\mathrm{pH}$ conditions in the background. It can be seen from Figure 7 that in the test $\mathrm{pH}$ range (2.0 6.0), the adsorption amount of $\mathrm{Pb}$ by $\mathrm{BC}$ and $\mathrm{K}$ $\mathrm{BC}$ increased first and then decreased. When the $\mathrm{pH}$ was 5 , the adsorption amount of $\mathrm{Pb}$ by $\mathrm{BC}$ and $\mathrm{K}-\mathrm{BC}$ reached the maximum. For $120.01 \mathrm{mg} \cdot \mathrm{g}^{-1}$ and $131.53 \mathrm{mg} \cdot \mathrm{g}^{-1}$. Different initial $\mathrm{pH}$ of the background solution have a greater effect on the adsorption of $\mathrm{Pb}$ by biochar. This is because when the $\mathrm{pH}$ value is low, a large amount of $\mathrm{H}^{+}$in solution will compete with $\mathrm{Pb}$ for adsorption (Liang et al., 2015). The negative charge relies on electrostatic adsorption of $\mathrm{H}^{+}$, which reduces the adsorption efficiency of $\mathrm{Pb}$ on biochar. With the increase of $\mathrm{pH}$, the concentration of $\mathrm{H}^{+}$in the solution gradually decreases, and the adsorption points on the surface and pore structure of biochar are fully exposed. Increasing the surface negative charge density provides more binding space for $\mathrm{Pb}$, thereby increasing the amount of adsorption.

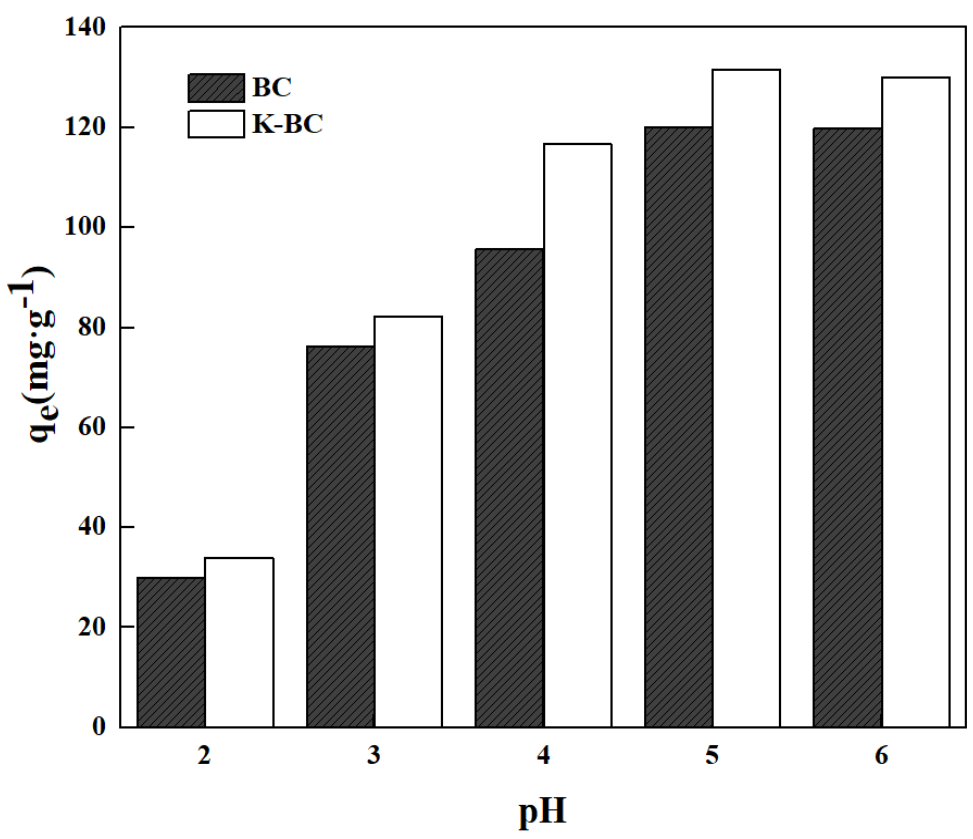

Figure 7. Adsorption of $P b$ by $B C$ and $K-B C$ under different $p H$ conditions. $B C$ and $K-B C$ adsorb $\mathrm{Pb}$ in equilibrium at different initial $\mathrm{pH}$ values. qe is the adsorption capacity $\mathrm{mg} \cdot \mathrm{g}^{-1}$ at equilibrium. The initial concentration of $P b$ was $400 \mathrm{mg} \cdot L^{-1}$, and the initial $\mathrm{pH}$ value was 2.0,

3.0, 4.0, 5.0 and 6.0. The test temperature was $15^{\circ} \mathrm{C}$ and the reaction time was $360 \mathrm{~min}$

\section{Conclusion}

In this study, corn stalks and $\mathrm{KOH}$ were used to impregnate corn stalks to prepare biochar. The adsorption characteristics of biochar on $\mathrm{Pb}$ were studied.

The research shows that:

(1) The adsorption process of $\mathrm{Pb}$ by $\mathrm{BC}$ and $\mathrm{K}-\mathrm{BC}$ is divided into two stages: fast and slow reaction. The adsorption equilibrium is reached in $360 \mathrm{~min}$. The quasi-secondorder kinetics can better evaluate the adsorption process.

The actual value is close.

With the increase of temperature, the adsorption of $\mathrm{Pb}$ by $\mathrm{BC}$ and $\mathrm{K}-\mathrm{BC}$ also increases. The Langmuir equation fits the adsorption effect optimally. The adsorption is spontaneous, endothermic and irreversible. 
When $\mathrm{pH}$ was 5 , the adsorption of $\mathrm{Pb}$ by $\mathrm{BC}$ and $\mathrm{K}-\mathrm{BC}$ reached the maximum.

(2) According to the structural characterization and physicochemical properties of $\mathrm{BC}$ and $\mathrm{K}-\mathrm{BC}$, the specific surface area of corn stalk charcoal was increased to $28.8272 \mathrm{~m}^{2} \cdot \mathrm{g}^{-1}$ by $\mathrm{KOH}$ modification. The total pore volume increased to $0.0136 \mathrm{~mL} \mathrm{~g}^{-1}$. The average particle size increased to $0.6878 \mathrm{~nm}$. It can be seen that the larger the specific surface area, the richer the pore structure, the more adsorption sites provided, the stronger the electrostatic adsorption capacity for $\mathrm{Pb}$; the higher the degree of aromatization, $\pi$ The more conjugated aromatic structures, the stronger the cation- $\pi$ interaction, and the greater the contribution rate to adsorption.

(3) Corn stalk biochar has a good adsorption effect on $\mathrm{Pb}$. Within the temperature and $\mathrm{pH}$ range designed in the experiment, the adsorption capacity of the two biochar for $\mathrm{Pb}$ is $\mathrm{K}-\mathrm{BC}>\mathrm{BC}$ and $\mathrm{KOH}$ modification can increase the adsorption amount of $\mathrm{Pb}$ on corn straw charcoal. This experiment lays the foundation theory and provides technical reference for the resource utilization of waste corn straw and the solution of heavy metal lead pollution in wastewater.

Acknowledgements. The Technological Development Project of Jilin Province (20200402013NC).

Conflict of interests. The authors declare no conflict of interests.

Data availability declarations. The authors state that [all other] data supporting the findings of this study can be found in the article [and its supplementary information files].

\section{REFERENCES}

[1] Abdallah, M. M., Ahmad, M. N., Walker, G. (2019): Batch and continuous systems for $\mathrm{Zn}, \mathrm{Cu}$, and $\mathrm{Pb}$ metal ions adsorption on spent mushroom compost biochar. - Industrial \& Engineering Chemistry Research. https://doi.org/10.1021/acs.iecr.9b00749.

[2] Abdelhafez, A. A., Li, J. H. (2016): Removal of Pb (II ) from aqueous solution by using biochars derived from sugar cane bagasse and orange peel. - Journal of the Taiwan Institute of Chemical Engineers 61: 367-375.

[3] Cao, Y., Xiao, W., Shen, G. (2018): Carbonization and ball milling on the enhancement of $\mathrm{Pb}$ (II) adsorption by wheat straw: competitive effects of ion exchange and precipitation. - Bioresource Technology. DOI: 10.1016/j.biortech.2018.10.065.

[4] Chen, J., Zhang, D., Wu, M. (2014): Elemental composition and thermal stability of two different biochar. - Environmental Chemistry 33(3): 417-422.

[5] Chi, T., Zuo, J., Liu, F. (2017): Performance and mechanism for cadmium and lead adsorption from water and soil by corn straw biochar. - Frontiers of Environmental Science \& Engineering. https://doi.org/10.1007/s11783-017-0921-y.

[6] Dai, C., Jia, P. (2019): Chlorogenic acid relieves lead-induced cognitive impairments and hepato-renal damage via regulating the dysbiosis of the gut microbiota in mice. - Food \& Function. https://doi.org/10.1039/C8FO01755G.

[7] Deng, J., Liu, Y., Liu, S. (2017): Competitive adsorption of $\mathrm{Pb}(\mathrm{II}), \mathrm{Cd}(\mathrm{II})$ and $\mathrm{Cu}$ (II) onto chitosan-pyromellitic dianhydride modified biochar. - Journal of Colloid and Interface Science 506: 355-364.

[8] Fahmi, A. H., Samsuri, A. W., Jol, H. (2018): Physical modification of biochar to expose the inner pores and their functional groups to enhance lead adsorption. - RSC Adv 8(67): 38270-38280.

[9] Gao, K., Jian, M., Yu, H. (2016): Effect of pyrolysis temperature on the biochars and its surface functional groups made from rice straw and rice busk. - Environmental Chemistry 35(8): 1663-1669. 
[10] Jian, M., Gao, K., Yu, H. (2015): Comparison of surface characteristics and cadmium solution adsorption capacity of un-acidified or acidified bio-chars prepared from rice straw under different temperatures. - Ecology and Environmental Sciences 24(8): 13751380.

[11] Kalderis, D., Kayan, B., Akay, S., Kulaksız, E., Gözmen, B. (2017): Adsorption of 2,4dichlorophenol on paper sludge/wheat husk biochar: process optimization and comparison with biochars prepared from wood chips, sewage sludge and hog fuel/demolition waste. - Journal of Environmental Chemical Engineering S2213343717301768.

[12] Komnitsas, K., Zaharaki, D., Bartzas, G. (2016): Efficiency of pecan shells and sawdust biochar on $\mathrm{Pb}$ and $\mathrm{Cu}$ adsorption. - Desalination \& Water Treatment 57(7): 3237-3246.

[13] Li, M., Wei, D., Liu, T., Yan, L., Wei, Q., Du, B., Xu, W. (2019): EDTA functionalized magnetic biochar for $\mathrm{Pb}(\mathrm{II})$ removal: adsorption performance, mechanism and SVM model prediction. - Separation \& Purification Technology 227. https://doi.org/10.1016/j.seppur.2019.115696.

[14] Liang, L., Wang, Y., Yan, Y. (2015): Adsorption property of $\mathrm{Cr}(\mathrm{VI})$ from aqueous solution by corncob and the SEM-EDS analysis on its characters. - Ecology and Environmental Sciences 24(2): 305-309.

[15] Liu, L., Huang, Y., Zhang, S. (2019): Adsorption characteristics and mechanism of Pb(II) by agricultural waste-derived biochars produced from a pilot-scale pyrolysis system. Waste Management 287-295.

[16] Mahdi, Z., Hanandeh, A. E., Yu, Q. J. (2019): Preparation, characterization and application of surface modified biochar from date seed for improved lead, copper, and nickel removal from aqueous solutions. - Journal of Environmental Chemical Engineering 7(5).

[17] Paranavithana, G. N., Kawamoto, K., Inoue, Y. (2016): Adsorption of $\mathrm{Cd}^{2+}$ and $\mathrm{Pb}^{2+}$ onto coconut shell biochar and biochar-mixed soil. - Environmental Earth Sciences 75(6): 484.

[18] Park, J. H., Wang, J. J., Kim, S. H. (2018): Lead sorption characteristics of various chicken bone part-derived chars. - Environmental Geochemistry and Health. DOI: 10.1007/s10653-017-0067-7.

[19] Peng, C., Xiao, T., Li, Z. (2017): Effects of pyrolysis temperature on structural properties of sludge-based biochar and its adsorption for heavy metals. - Research of Environmental Sciences. DOI: 10.13198/j.issn.1001-6929.2017.02.95.

[20] She, S., Huang, H., Guan, C. (2016): Study on the carbon sink function of crop production in typical agricultural areas of China. - Engineering sciences 18(1): 106.

[21] Shen, Z., Zhang, J., Hou, D. (2018): Synthesis of MgO-coated corncob biochar and its application in lead stabilization in a soil washing residue. - Environment International 122: $357-362$.

[22] Sing, K. S. W., Everett, D. H., Haul, R. A. W. (1985): Reporting physisorption data for gas/solid systems with special reference to the determination of surface area and porosity. - Pure \& Appl. Chem. 57(4): 603-619.

[23] Wang, L., Zhao, B., Ma, F. (2016): Effects of biochar derived from potato straw on adsorption of $\mathrm{Cd}(\mathrm{II})$ onto loess. - Environmental Chemistry 5(7): 1422-1430 (in Chinese).

[24] Wang, Z., Fei, S., Shen, D. (2017a): Immobilization of $\mathrm{Cu}^{2+}$ and $\mathrm{Cd}^{2+}$ by earthworm manure derived biochar in acidic circumstance. - Journal of Environmental Science 53(3): 293-300.

[25] Wang, T., Ma, J., Qu, D. (2017b): Characteristics and mechanism of copper adsorption from aqueous solutions on biochar produced from sawdust and apple branch. Environmental Science 38(5): 2161-2171. 
[26] Wang, W., Ma, X., Sun, J. (2019): Adsorption of enrofloxacin onacid/alkali-modified corn stalk biochar. - Spectroscopy Letters 52(7): 367-375.

[27] Xiao, X., Chen, B., Chen, Z. (2018): insight into multiple and multilevel structures of biochars and their potential environmental applications: a critical review. Environmental Science \& Technology 52(9): 5027-5047.

[28] Yang, W., Wang, Z., Song, S. (2019): Adsorption of copper (II) and lead(II) from seawater using hydrothermal biochar derived from Enteromorpha. - Marine Pollution Bulletin 149: 110586.

[29] Zhang, L., Liu, X., Huang, X. (2019b): Adsorption of $\mathrm{Pb}^{2+}$ from aqueous solutions using Fe-Mn binary oxides-loaded biochar: kinetics, isotherm and thermodynamic studies. Environmental Technology 40(13-16): 1853-1861.

[30] Zhang, L., Tang, S., He, F. (2019a): Highly efficient and selective capture of heavy metals by poly(acrylic acid) grafted chitosan and biochar composite for wastewater treatment. - Chemical Engineering Journal. https://doi.org/10.1016/j.cej.2019.122215.

[31] Zhao, M., Dai, Y., Zhang, M. (2020): Mechanisms of Pb and/or Zn adsorption by different biochars: biochar characteristics, stability, and binding energies. - Science of the Total Environment 717: 136894.

[32] Zhu, J., Baig, S. A., Sheng, T. T. (2015): $\mathrm{Fe}_{3} \mathrm{O}_{4}$ and $\mathrm{MnO}_{2}$ assembled on honeycomb briquette cinders (HBC) for arsenic removal from aqueous solutions. - Journal of Hazardous Materials 286: 220-228. 